\title{
Análisis Físico-Químico y Morfológico de Almidones de Ñame, Yuca y Papa y Determinación de la Viscosidad de las Pastas
}

Armando Alvis ${ }^{1 *}$, Carlos A. Vélez ${ }^{2}$, Héctor S. Villada ${ }^{3}$ y Maite Rada-Mendoza ${ }^{4}$

(1) Universidad de Córdoba, Facultad de Ciencias Agrícolas, Departamento de Ingeniería de Alimentos, Carrera 6 No. 76-103, Km 3, vía Cereté, Córdoba-Colombia

(e-mail: aalvis2@hotmail.com)

(2) Universidad del Valle, Facultad de Ingeniería, Departamento de Ingeniería de Alimentos, Apartado Aéreo 25360, Cali-Colombia

Universidad del Cauca, (3), Facultad de Ciencias Agropecuarias, Departamento de Agroindustria,

(4) Facultad de Ciencias Naturales, Exactas y de la Educación, Departamento de Química,

Calle 5 No. 4-70. Popayán, Cauca-Colombia.

* autor a quien debe ser dirigida la correspondencia

\section{Resumen}

Se estudiaron las propiedades fisicoquímicas y la morfología y los viscoamilogramas de cuatro almidones nativos de ñame, tres de yuca y uno de papa, Previo a las determinaciones, las muestras fueron secadas hasta peso constante. El contenido de cenizas y amilosa, la temperatura de gelatinización y la viscosidad fue inferior en yuca; la grasa mostró diferencias entre yuca y papa; el índice de absorción de agua en ñame, papa y yuca, mostró diferencias significativas. En el índice de solubilidad en agua no se apreciaron diferencias significativas entre ñame y papa. La facilidad de cocción fue similar en ñame y papa; el incremento en la viscosidad de la pasta fue mayor en ñame y papa. Igualmente, se observaron diferencias en la forma y tamaño del gránulo. Estos cambios en las propiedades, la viscosidad y la morfología, pueden influir en la fabricación y producción de productos alimentarios y no alimentarios derivados de estos almidones.

\section{Physicochemical and Morphological Analyses of Yam, Cassava and Potato Starches and Determination of their Viscosity}

\begin{abstract}
The physicochemical properties, morphology and the viscoamilogrames of yam, potato and cassava native starches were studied. Previous the determinations, the samples were dried up to constant weight. Ash and amylose content, gelatinization temperature and viscosity were lower in cassava; fat showed differences between cassava and potato; water absorption index in yam, potato and cassava showed significant differences. Cooking facility was similar in yam and potato; the increase in paste viscosity was greater in yam and potato. Also, it was observed differences in shape and size granule. These changes in properties, viscosity and morphology can influence the manufacture of food and non-food products derived from these starches.
\end{abstract}

Keywords: starch, yam, potato and cassava physicochemical properties, viscosity, morphology 


\section{INTRODUCCIÓN}

Raíces y tubérculos como el ñame, yuca y papa son alimentos básicos en la alimentación en algunos países a nivel mundial; a partir de ellos, se pueden fabricar productos de panadería y un gran número de alimentos tradicionales (Jinsong et al., 2006).

El ñame (Dioscorea alata), se cultiva principalmente en el occidente de África, Asia y el Caribe. En Colombia se encuentra en la región de la Costa Atlántica, donde se cultivan alrededor de 29757 ha, que involucran a 9000 familias de pequeños productores cuyo sistema de comercialización se caracteriza por bajos volúmenes, escasa infraestructura de acopio, transporte y almacenamiento y una reducida transformación, donde el $78 \%$ de la producción se dirige al mercado en fresco; no se conocen transformaciones tecnológicas. El almidón nativo de ñame posee una resistencia excepcional a la esterilización, lo que lo convierte en un recurso potencial para el desarrollo de productos que necesiten largos períodos de cocción (DANE, 2004; Rodríguez, 2000).

La yuca (Manihot sculenta), pertenece a una especie de raíces amiláceas que en Colombia se cultiva hasta los $2000 \mathrm{~m}$ de altura; se utiliza para el consumo animal, humano e industrial y en la producción de almidón y harina (DANE, 2004).

La papa (Solanum tuberosum), es un tubérculo de una legumbre farinácea que se cultiva en zonas con un alto nivel freático. En Colombia, la producción comercial se realiza entre los 2000 y $3000 \mathrm{~m}$ sobre el nivel del mar (m.s.n.m) (DANE, 2004).

Uno de los mayores componentes de las raíces y tubérculos es el almidón, el cual constituye la mayor fuente energética de las plantas (Martín y Smith, 1995); sus gránulos tienen diferentes tamaños (diámetros entre 10 a $100 \mu \mathrm{m}$ ) y formas (redonda, elíptica, ovalada, lenticular o poligonal) dependiendo de la fuente biológica de donde provengan y son parcialmente semicristalinos e insolubles en agua a temperatura ambiente (Bello et al., 1998; Vandeputte y Delcour, 2004). Su contenido de amilosa y amilopectina, temperatura de gelatinización, consistencia del gel y textura, comportamiento viscoso y propiedades térmicas, permite su utilización en la industria alimenticia como estabilizante, agente de relleno, adhesivo, ligante, enturbiante, formador de películas, estabilizante de espumas, agente de antienvejecimiento de pan, gelificante, glaseante, humectante y espesante (Singh et al., 2005).

La superficie de los diferentes gránulos del almidón, varía según el origen botánico y constituyen un interrogante en investigaciones (Lindeboom et al., 2004); una de las técnicas ópticas más usadas para caracterizarlos es el microscopio óptico de alta resolución (M.O.A.R), que da una imagen virtual amplificada de un objeto pequeño; esta técnica puede combinarse con dispositivos de control de imágenes tales como contraste diferencial de interferencia (DIC), el cual permite observar especimenes sin necesidad de tinción (Fiedorowicz et al., 2002).

El objetivo del presente trabajo fue evaluar las características fisico-químicas y la morfología de los almidones nativos de ñame, yuca y papa; adicionalmente, se determinó la viscosidad de las pastas, con el objeto de conocer las diferentes características de los almidones obtenidos a partir de materiales autóctonos, requeridos en el procesamiento de alimentos específicos usados en la alimentación humana y animal (DANE, 2004; Martínez, 2005).

\section{MATERIALES Y MÉTODOS}

\section{Materiales}

Se han empleado almidones obtenidos a partir de cuatro variedades de ñame (Pico de Botella, Diamante 22, Bolañero y Ecuatoriana) suministradas por la Universidad de Córdoba (Montería, Córdoba, Colombia); tres variedades de yuca (ICA-Catumare 523-7, HCM-1 y MBRA-383), suministradas por el Centro Internacional de Agricultura Tropical (CIAT, Palmira, Colombia) y una variedad de papa (ICA-Nariño), suministrada por la Rallandería Yarumal (La Agustina, Cauca, Colombia). 


\section{Preparación de las muestras}

Previo a la determinación del análisis proximal, las muestras fueron secadas en una estufa de vacío (VWR Scientific) a $55^{\circ} \mathrm{C}$ durante 16 horas hasta peso constante.

\section{Propiedades fisico-químicas}

La humedad, fibra, cenizas, grasa y proteína, fueron determinadas siguiendo el procedimiento de la AOAC (2003). El índice de absorción de agua (IAA) y el índice de solubilidad en agua (ISA), se determinaron usando la técnica de Anderson (Anderson et al., 1970). El contenido de amilosa se determinó usando la norma técnica ISO 6647 (1987).

\section{Viscoamilogramas}

La temperatura de gelatinización y las curvas de empastamiento, se determinaron utilizando un Rapid Visco Analyzer RVA [Serie 4, New-port Scientific, Sydnei, Australia]. Se preparó una solución de almidón al $5 \%(\mathrm{p} / \mathrm{v})$ en base seca y se utilizó agua destilada; directamente en los recipientes del RVA, se colocaron las paletas y se mezcló. Una vez hecho esto, se bajó la torre del motor del equipo y se empezó el ciclo de medida; el perfil de temperatura utilizado para el análisis de los almidones de yuca, papa y ñame fue el siguiente:

1. Se inició a $25^{\circ} \mathrm{C}$ y se agitó durante 10 segundos.

2. Se calentó a una velocidad constante de $1,5^{\circ} \mathrm{C} / \mathrm{min}$ hasta alcanzar los $90^{\circ} \mathrm{C}$.

3. La temperatura permaneció constante en $90^{\circ} \mathrm{C}$ durante 20 minutos.

4. Se enfrió a una velocidad de $1,5^{\circ} \mathrm{C} / \mathrm{min}$ hasta $50^{\circ} \mathrm{C}$.

5. Por último, la temperatura permaneció constante en $50{ }^{\circ} \mathrm{C}$ durante 10 minutos. Estos análisis se realizaron en el laboratorio de Agroempresas CIAT-Palmira, Valle del Cauca (Colombia).

\section{Microscopía óptica de alta resolución}

Para el análisis de almidones, se utilizó un microscopio óptico de alta resolución M.O.A.R (Nikon Microphot, Japón) con software Leica Qwin 550. Las muestras se observaron en 20x. Se utilizó la técnica de contraste diferencial de interferencia (DIC), dado que esta técnica aprovecha las diferencias en el índice de refracción y el espesor de la muestra, permitiendo determinar la topografía del objeto de estudio (Toshio et al., 2000).

\section{RESULTADOS Y DISCUSIÓN}

\section{Propiedades fisico-químicas}

La Tabla 1, muestra los valores obtenidos del análisis fisico-químico de los almidones nativos de ñame, yuca y papa.

El contenido de humedad en los cuatro almidones de ñame fue entre 8,66 a 10,22 \%, entre 7,80 a $8,47 \%$ en las tres variedades de yuca y 8,50 \% en la variedad de papa; estos resultados están acordes con la información reportada en la literatura para almidón nativo de ñame que varía entre 10,00 a 10,40 \% (Jinsong et al., 2006), yuca, los cuales varían entre 5,00 a 13,74\% (Alarcón y Dufour, 1998; Hoover, 2001; Sangeetha, 2006) y para almidón nativo de papa entre 7,00 a 13,3\% (Hoover, 2001; Sangeetha, 2006).

En los almidones nativos de yuca y papa no se observa ninguna diferencia significativa en el contenido de fibra $(0,05 \%$ en yuca y $0,05 \%$ en papa) y estos resultados son similares a los reportados en la literatura (Petnamsin et al., 2000; Shamekin et al., 2002); sin embargo, con respecto a los almidones de ñame sí hay diferencia en el contenido de fibra. Estos resultados son similares a otro trabajo, donde se reportó que la cantidad de fibra cruda en almidones de ñame criollo y espino fue del 0,0\% (Rodríguez, 2000). 
Tabla 1: Análisis proximal en almidones nativos de ñame, yuca y papa. Valoración del (\%) de amilosa IAA e ISA. Valores por triplicado y un $(p<0,05)$.

\begin{tabular}{|c|c|c|c|c|c|c|c|c|}
\hline $\begin{array}{c}\text { Variedad } \\
\text { de almidón }\end{array}$ & $\begin{array}{l}\text { Humedad } \\
\text { (\%) }\end{array}$ & $\begin{array}{l}\text { Fibra } \\
(\%)\end{array}$ & $\begin{array}{c}\text { Ceniza } \\
\text { (\%) }\end{array}$ & $\begin{array}{c}\text { Grasa } \\
(\%)\end{array}$ & $\begin{array}{l}\text { Proteína } \\
\text { (\%) }\end{array}$ & $\begin{array}{c}\text { Amilosa } \\
(\%)\end{array}$ & $\begin{array}{c}\text { IAA } \\
(\mathrm{g} \text { gel/g } \\
\text { muestra (BS)) }\end{array}$ & $\begin{array}{c}\text { ISA } \\
\text { (g soluble/ g } \\
\text { muestra (BS)) }\end{array}$ \\
\hline \multicolumn{9}{|l|}{ Ñame } \\
\hline Bolañero & $\begin{array}{c}9,75 \\
\pm 0,07 \\
\end{array}$ & $\begin{array}{c}0,00 \\
\pm 0,00\end{array}$ & $\begin{array}{c}0,39 \\
\pm 0,01 \\
\end{array}$ & $\begin{array}{c}0,00 \\
\pm 0,00 \\
\end{array}$ & $\begin{array}{c}0,10 \\
\pm 0,00 \\
\end{array}$ & $\begin{array}{r}27,89 \\
\pm 0,26 \\
\end{array}$ & $\begin{array}{c}2,33 \\
\pm 0,01 \\
\end{array}$ & $\begin{array}{c}2,11 \\
\pm 0,20 \\
\end{array}$ \\
\hline Diamante22 & $\begin{array}{r}10,09 \\
\pm 0,11 \\
\end{array}$ & $\begin{array}{r}0,00 \\
\pm 0,00 \\
\end{array}$ & $\begin{array}{c}0,36 \\
\pm 0,06 \\
\end{array}$ & $\begin{array}{r}0,00 \\
\pm 0,00 \\
\end{array}$ & $\begin{array}{r}0,28 \\
\pm 0,01 \\
\end{array}$ & $\begin{array}{r}27,55 \\
\pm 0,36 \\
\end{array}$ & $\begin{array}{r}2,39 \\
\pm 0,04 \\
\end{array}$ & $\begin{array}{r}1,90 \\
\pm 0,18 \\
\end{array}$ \\
\hline Ecuatoriano & $\begin{array}{r}8,66 \\
\pm 0,05 \\
\end{array}$ & $\begin{array}{c}0,00 \\
\pm 0,00 \\
\end{array}$ & $\begin{array}{r}0,45 \\
\pm 0,03 \\
\end{array}$ & $\begin{array}{c}0,06 \\
\pm 0,01 \\
\end{array}$ & $\begin{array}{c}0,13 \\
\pm 0,01 \\
\end{array}$ & $\begin{array}{r}25,87 \\
\pm 0,24 \\
\end{array}$ & $\begin{array}{r}2,39 \\
\pm 0,04 \\
\end{array}$ & $\begin{array}{r}1,25 \\
\pm 0,02 \\
\end{array}$ \\
\hline $\begin{array}{l}\text { Pico de } \\
\text { Botella }\end{array}$ & $\begin{array}{r}10,22 \\
\pm 0,04 \\
\end{array}$ & $\begin{array}{c}0,00 \\
\pm 0,00 \\
\end{array}$ & $\begin{array}{c}0,69 \\
\pm 0,04 \\
\end{array}$ & $\begin{array}{c}0,06 \\
\pm 0,00 \\
\end{array}$ & $\begin{array}{c}0,49 \\
\pm 0,01 \\
\end{array}$ & $\begin{array}{r}25,95 \\
\pm 0,15 \\
\end{array}$ & $\begin{array}{r}2,32 \\
\pm 0,02 \\
\end{array}$ & $\begin{array}{r}2,79 \\
\pm 0,22 \\
\end{array}$ \\
\hline \multicolumn{9}{|l|}{ Yuca } \\
\hline ICA-C523-7 & $\begin{array}{r}8,47 \\
\pm 0,15 \\
\end{array}$ & $\begin{array}{c}0,04 \\
\pm 0,01 \\
\end{array}$ & $\begin{array}{r}0,15 \\
\pm 0,00 \\
\end{array}$ & $\begin{array}{c}0,31 \\
\pm 0,00 \\
\end{array}$ & $\begin{array}{c}0,60 \\
\pm 0,02 \\
\end{array}$ & $\begin{array}{r}14,67 \\
\pm 0,25 \\
\end{array}$ & $\begin{array}{r}4,80 \\
\pm 0,00 \\
\end{array}$ & $\begin{array}{r}3,70 \\
\pm 0,00 \\
\end{array}$ \\
\hline HCM-1 & $\begin{array}{r}7,80 \\
\pm 0,8 \\
\end{array}$ & $\begin{array}{c}0,05 \\
\pm 0,01 \\
\end{array}$ & $\begin{array}{c}0,16 \\
\pm 0,01 \\
\end{array}$ & $\begin{array}{c}0,30 \\
\pm 0,01 \\
\end{array}$ & $\begin{array}{c}0,61 \\
\pm 0,02 \\
\end{array}$ & $\begin{array}{r}14,23 \\
\pm 0,55 \\
\end{array}$ & $\begin{array}{c}4,77 \\
\pm 0,12 \\
\end{array}$ & $\begin{array}{r}3,67 \\
\pm 0,21 \\
\end{array}$ \\
\hline MBra 383 & $\begin{array}{r}7,80 \\
\pm 0,31 \\
\end{array}$ & $\begin{array}{c}0,05 \\
\pm 0,01 \\
\end{array}$ & $\begin{array}{c}0,11 \\
\pm 0,02 \\
\end{array}$ & $\begin{array}{c}0,32 \\
\pm 0,01 \\
\end{array}$ & $\begin{array}{c}0,60 \\
\pm 0,03 \\
\end{array}$ & $\begin{array}{r}14,43 \\
\pm 0,51 \\
\end{array}$ & $\begin{array}{c}4,63 \\
\pm 0,23 \\
\end{array}$ & $\begin{array}{c}2,60 \\
\pm 0,10 \\
\end{array}$ \\
\hline \multicolumn{9}{|l|}{ Papa } \\
\hline ICA Nariño & $\begin{array}{r}8,50 \\
\pm 0,26 \\
\end{array}$ & $\begin{array}{c}0,05 \\
\pm 0,00\end{array}$ & $\begin{array}{c}0,44 \\
\pm 0,03\end{array}$ & $\begin{array}{c}0,35 \\
\pm 0,02\end{array}$ & $\begin{array}{c}0,62 \\
\pm 0,01 \\
\end{array}$ & $\begin{array}{r}24,00 \\
\pm 0,00\end{array}$ & $\begin{array}{r}5,83 \\
\pm 0,33 \\
\end{array}$ & $\begin{array}{r}2,97 \\
\pm 0,12 \\
\end{array}$ \\
\hline
\end{tabular}

Los resultados muestran diferencias significativas importantes en el contenido de ceniza entre los almidones de ñame y papa con respecto a los de yuca que fueron más bajos (entre 0,11 y 0,16 \%). En ñame, la variedad Pico de Botella presentó la mayor cantidad de cenizas, 0,69\%, seguido del Ecuatoriano con 0,45 \%. La papa ICA-Nariño mostró un contenido de 0,44 \% y este valor está por encima de los valores encontrados para los almidones de ñame Bolañero con 0,39 \% y Diamante 22 con $0,36 \%$. El aumento en la cantidad de cenizas se relaciona posiblemente con un aumento en el contenido de minerales en los almidones de ñame y papa. Estos resultados son similares a los reportados en la literatura y en las cuales, además se reporta que el contenido de fósforo y de algunos minerales en papa y ñame influyen en el contenido final de las cenizas (Hoover, 2002).

El contenido de grasa mostró diferencias entre los almidones de ñame, yuca y papa. En las tres variedades de yuca no se presentaron diferencias e incluso con papa; los valores encontrados estuvieron entre 0,30 a 0,35 \%. Estos resultados concuerdan con otros trabajos de investigación, donde en yuca se reportaron contenidos entre 0,30 a 0,38 \% y en papa entre 0,30 a 0,40 \% (Huang, 2001). En ñame, las variedades Bolañero y Diamante 22 no contienen grasa, mientras que las variedades Ecuatoriano y Pico de Botella contienen 0,06 \%. Estos resultados concuerdan con lo reportado en trabajos realizados con almidones de ñame con contenidos entre 0,00 a 0,05\% (Hoover, 2002).

La proteína presente en el almidón nativo de yuca y papa no presenta diferencias, encontrándose contenidos entre 0,60 a 0,62 \%; estos resultados son similares a los de otra investigación, donde se reportan contenidos de proteína de 0,59 y 0,61 \% para almidones de yuca y papa, respectivamente. Entre los almidones de ñame se presentaron diferencias, variando sus contenidos entre 0,10 a 0,49 $\%$; resultados semejantes fueron reportados en otro estudio, hallándose contenidos de proteína de 0,50 \% para ñame criollo y espino (Rodríguez, 2000).

La relación amilosa/amilopectina, imparte características definitivas en las propiedades funcionales de los almidones, dada la aplicación específica que se puede dar de éste en un desarrollo de un producto. La amilosa se caracteriza porque favorece la retrogradación de sus pastas durante el enfriamiento, ocasionando el indeseable fenómeno de sinéresis, mientras que la amilopectina presenta pastas espesas que no se retrogradan fácilmente al enfriarse (Hoover, 2002). En la Tabla 1 se muestra la variación en el contenido de amilosa entre almidones de yuca, ñame y papa. El contenido de amilosa en almidón de ñame fue similar al del almidón de papa; en ñame varió entre 
25,87 a $27,89 \%$, y en papa fue del 24,0 \%. A diferencia de los dos anteriores, los almidones de yuca mostraron un contenido inferior, que varió entre 14,23 a 14,67\%; en algunas investigaciones se reportó que el contenido de amilosa para almidones nativos de yuca variaron entre 14 a $19 \%$ (Hoover, 2002), en almidones de papa entre el 22 a 26 \% (Hoover, 2001) y en almidones de ñame entre el 27 a $29 \%$ (Hoover, 2002). Estas diferencias encontradas en el contenido de amilosa, se deben a la fuente biológica de donde provienen los almidones.

En el IAA de los almidones de ñame, yuca y papa, se presentaron diferencias significativas; en las cuatro variedades de almidones de ñame, este valor varió entre 2,32 a 2,39; en almidón de papa fue de 5,83 y los almidones de yuca variaron entre 4,63 a 4,80. Estas diferencias en el IAA de almidones nativos de ñame, papa y yuca, puede estar relacionada con la fuente biológica, con el tamaño y la forma del gránulo (Lindeboom et al., 2004).

En el ISA, no se apreció una amplia diferencia significativa entre los almidones de ñame, yuca y papa. ISA en los almidones de ñame varió entre 1,25 a 2,79 \%, en yuca entre 2,60 a 3,70 \% y en papa fue del 2,97\%. La escasa diferencia en el ISA de los almidones nativos de ñame y papa con respecto a los de yuca es posible que se deba al menor contenido de amilopectina presente en los almidones nativos de yuca. Investigadores plantearon la posibilidad de que las ramificaciones laterales (amilopectina) de las moléculas del almidón y un menor tamaño del gránulo, facilitan la entrada del agua a los espacios intermoleculares, aumentando la solubilidad de los polímeros, siendo la amilopectina la de mayor proporción de disolución. Esto desde luego, incide en el aumento de solubilidad de las moléculas en el agua y en la estabilidad de la viscosidad (Hwang y Kokini, 1992).

\section{Viscoamilogramas}

Durante el experimento en el RVA (Rapid Visco Analyzer), se obtuvo para cada muestra: la viscosidad relativa (RVU) en función de su temperatura y el tiempo del experimento, los índices de inestabilidad de gel (o breakdown) y estabilidad de gel (o setback) dados en RVU, siendo estas variables registradas automáticamente en una computadora acoplada al RVA; además, se consideraron los resultados de la facilidad de cocción en minutos (min.). En la Tabla 2, se muestran los resultados obtenidos de los almidones nativos de ñame, papa y yuca.

Tabla 2: Datos promedios de viscoamilogramas de cuatro tipos de almidón nativo de ñame, tres de yuca y uno de papa (ver Fig. 1).

\begin{tabular}{|l|c|c|c|c|c|}
\hline $\begin{array}{c}\text { Variedad de } \\
\text { almidón }\end{array}$ & $\begin{array}{c}\text { Temperatura de } \\
\text { gelatinización } \\
\left({ }^{\circ} \mathrm{C}\right)\end{array}$ & $\begin{array}{c}\text { Viscosidad } \\
\text { máxima } \\
(\mathrm{RVU})\end{array}$ & $\begin{array}{c}\text { Facilidad de } \\
\text { cocción } \\
(\mathrm{min})\end{array}$ & $\begin{array}{c}\text { Índice de } \\
\text { inestabilidad de gel } \\
(\mathrm{RVU})\end{array}$ & $\begin{array}{c}\text { Índice de } \\
\text { estabilidad de gel } \\
(\mathrm{RVU})\end{array}$ \\
\hline Ñame \\
\hline Bolañero & $78 \pm 0$ & $369 \pm 17$ & $3,12 \pm 0,15$ & $80 \pm 21$ & $73 \pm 2$ \\
\hline Diamante 22 & $79 \pm 0$ & $282 \pm 0$ & $2,32 \pm 0,07$ & $95 \pm 1$ & $83 \pm 2$ \\
\hline Ecuatoriano & $77 \pm 2$ & $435 \pm 5$ & $2,91 \pm 0,36$ & $64 \pm 5$ & $111 \pm 2$ \\
\hline Pico de Botella & $75 \pm 2$ & $221 \pm 1$ & $3,36 \pm 0,28$ & $33 \pm 1$ & $21 \pm 1$ \\
\hline Yuca & $61 \pm 1$ & $62 \pm 0$ & $4,50 \pm 0,35$ & $13 \pm 0$ & $12 \pm 0$ \\
\hline ICA-C523-7 & $62 \pm 0$ & $62 \pm 0$ & $4,83 \pm 0,15$ & $13 \pm 0$ & $12 \pm 0$ \\
\hline HCM-1 & $63 \pm 0$ & $65 \pm 0$ & $4,83 \pm 0,21$ & $16 \pm 0$ & $16 \pm 0$ \\
\hline MBra-383 & $66 \pm 2$ & $119 \pm 0$ & $3,40 \pm 0,10$ & $11 \pm 0$ & $11 \pm 0$ \\
\hline Papa
\end{tabular}

La temperatura media de gelatinización de los almidones de yuca fue de $62{ }^{\circ} \mathrm{C}$, y está en concordancia con el reportado en la literatura para almidones nativos de yuca entre 58 y $65^{\circ} \mathrm{C}$. En el caso del almidón nativo de papa, la temperatura de galatinización fue de $66{ }^{\circ} \mathrm{C}$; esta temperatura está en concordancia con los rangos reportados en la literatura para almidón nativo de papa entre 56 
y $67{ }^{\circ} \mathrm{C}$ (Lindeboom et al., 2004). Las variedades de ñame nativo presentaron un rango de temperatura de gelatinización entre 75 y $79^{\circ} \mathrm{C}$, muy cercano al reportado en otra investigación que tiene rangos entre 75 y $86^{\circ} \mathrm{C}$ para ñame criollo y espino (Rodríguez, 2000). Una mayor temperatura de gelatinización en almidones nativos, refleja una mayor estabilidad interna del gránulo de almidón, normalmente asociada a una mayor presencia de zonas semicristalinas y a un mayor contenido de amilosa (Imberty et al., 1988); además, se reportó que la temperatura de gelatinización en raíces y tubérculos es menor que en cereales porque el gránulo de almidón absorbe rápidamente agua debido al debilitamiento entre las fuerzas de atracción de las moléculas (amilosa/amilopectina), fenómeno asociado a una menor presencia de amilosa y a una mayor presencia de regiones cristalinas dentro del gránulo que requieren menos temperatura de calentamiento.

Como se observa en la Figura 1(a) y Tabla 2, la viscosidad máxima en las variedades de los almidones nativos de ñame, presentó diferencias significativas. Las variedades Pico de Botella y Diamante 22 arrojaron viscosidades de 221 y 282 RVU respectivamente y las variedades ecuatoriano y Bolañero, 435 y 369 RVU, respectivamente; lo anterior se explica por la relación entre el contenido de amilosa/amilopectina en los diferentes almidones de ñame, papa y yuca y el tamaño del gránulo. La viscosidad máxima en los almidones nativos de yuca no presentó diferencias significativas; esto se explica por la estrecha relación existente entre el contenido de amilosa/amilopectina presente en las tres variedades de yuca como se mostró en la Figura 1(b). La viscosidad máxima del almidón nativo de papa fue de $119 \mathrm{RVU}$.

Las marcadas diferencias en las curvas de empastamiento (viscoamilogramas) entre los almidones son obvias, debido a la fuente biológica. La formación del gel depende de la asociación de los polímeros, especialmente de la fracción de amilosa presente en las moléculas, del tamaño y de la forma del gránulo.

En los almidones nativos de ñame y papa, la facilidad de cocción fue similar en comparación con los almidones nativos de yuca; en los almidones de ñame varió entre 2,32 a 3,36 min y en papa fue de 3,40 min. En los almidones de yuca estos valores fueron mayores, entre 4,50 a 4,83 min. Esta diferencia de comportamiento en la facilidad de cocción, se puede atribuir al hecho de que hay una mayor presencia de gránulos de almidón de yuca que ocupan una mayor área superficial en la solución, mientras que los gránulos de almidón de ñame y papa inciden directamente en un tiempo mayor en relación a la facilidad de cocción de la pasta (Hoover, 2002).

Los índices de inestabilidad y estabilidad del gel, presentan un decrecimiento en los almidones nativos de yuca entre 13 a $16 \mathrm{RVU}$ y 12 a $16 \mathrm{RVU}$, respectivamente y en papa que fue de 11 RVU para ambos índices, en comparación con ñame el cual fue de 33 a 95 RVU y 21 a 111 RVU, respectivamente. Estas diferencias se deben a una menor presencia de amilopectina en el almidón nativo de papa y ñame, que es el polímero que rápidamente se solubiliza en el medio acuoso y da estabilidad viscoelástica a la curva de empastamiento cuando dicha solución es sometida a cambios bruscos de temperatura (Wang et al., 2003).

El incremento en la viscosidad de la pasta que ocurre al finalizar la curva de empastamiento como se observa en las curvas de los viscoamilogramas mostrados en la Figura 1, se relacionan con el enfriamiento de la pasta y se asocia con el fenómeno de retrogradación y con el contenido de amilosa que es menor en los almidones de yuca que en ñame y papa. Este fenómeno de la retrogradación se ve influenciado por varios factores: el contenido de amilosa, la longitud de las cadenas (moléculas) de amilosa y el estado de dispersión de las cadenas de amilosa (Hoover, 2002).

\section{Microscopía óptica de almidones nativos}

La Figura 2 muestra las microfotografías obtenidas para los almidones nativos de yuca, papa y ñame. Se trabajó una sola técnica de M.O.A.R, contraste diferencial de interferencia (DIC). Esta técnica permitió observar los cambios en forma y tamaño en los gránulos de almidón de yuca, papa y ñame. Las flechas señalan las formas regulares de los gránulos nativos del almidón de yuca (esférica y re- 


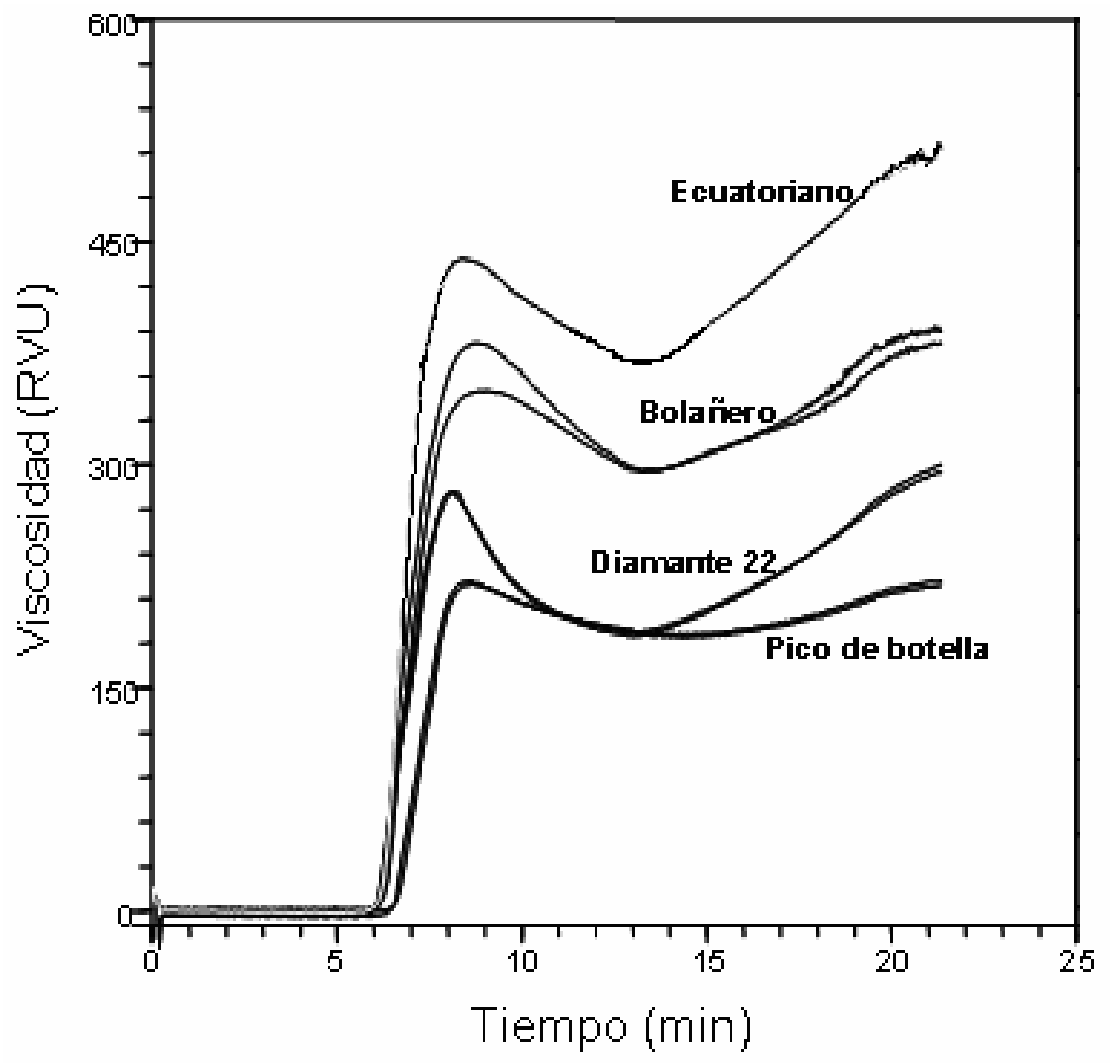

(a)

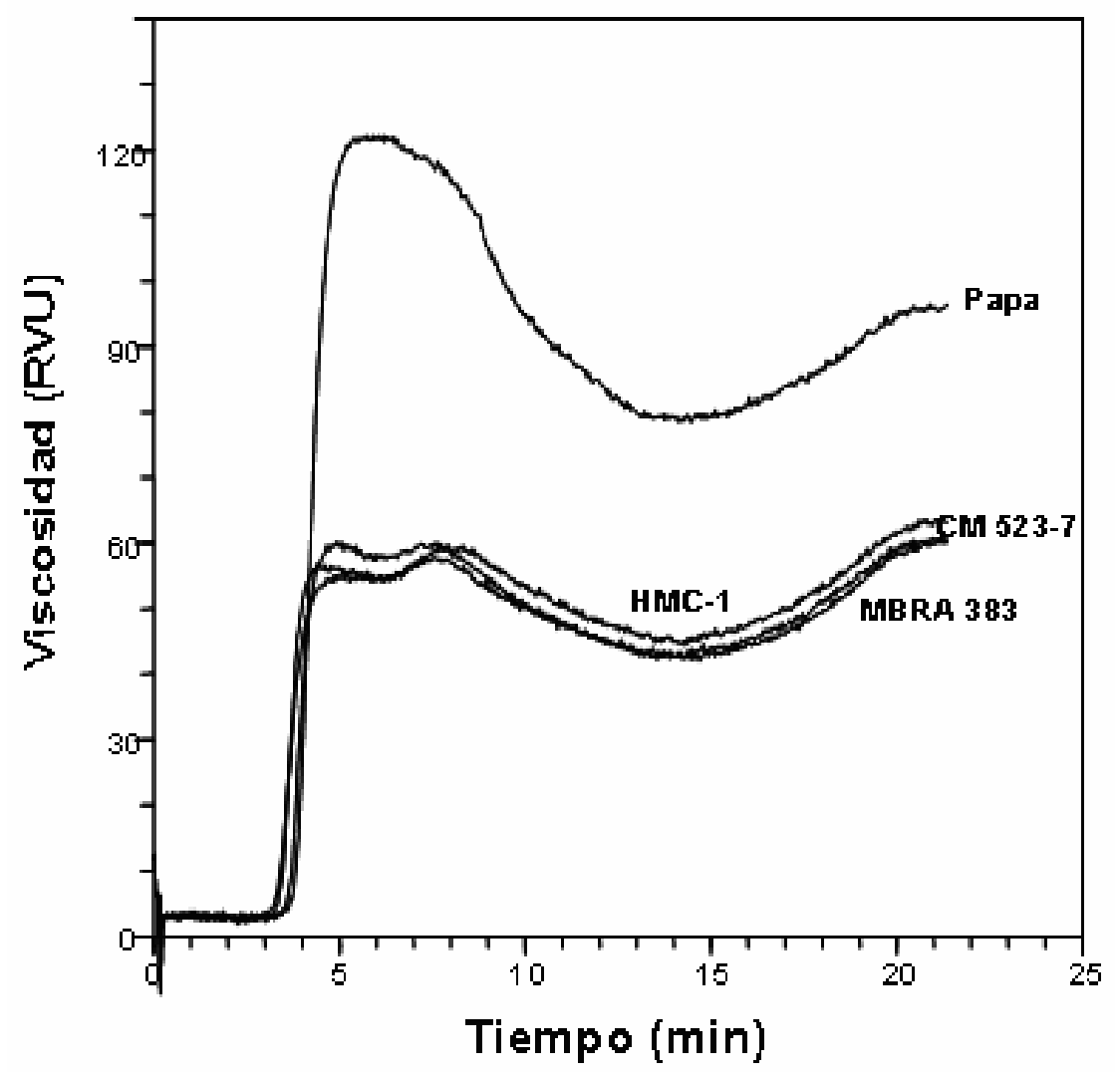

(b)

Fig.1: Viscoamilogramas de almidones nativos: (a). ñame, (b). papa y yuca. 

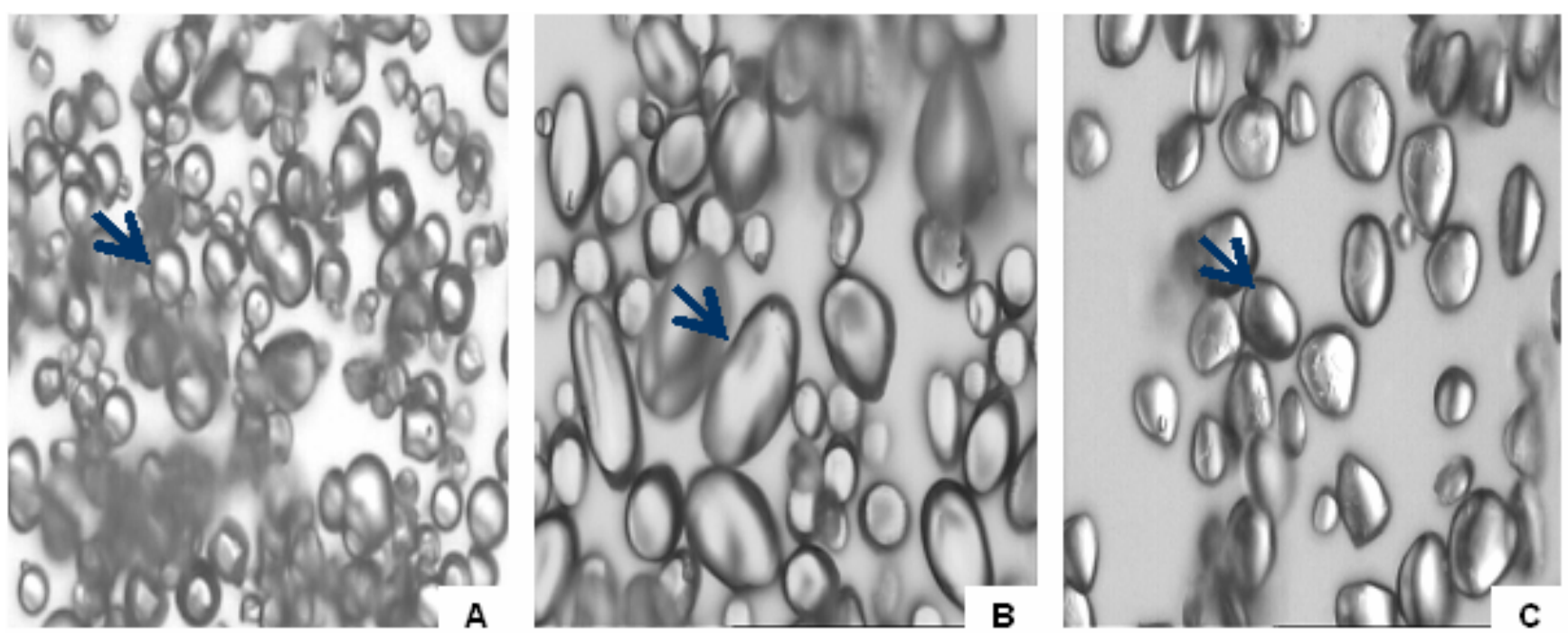

Fig. 2: Microfotografías 20x. Almidones nativos: A. Yuca, B. Papa, C. Ñame.

donda), papa (ovoide y redonda) y ñame (lenticular y redonda). La Figura 2A, muestra los gránulos de almidón nativo de yuca esféricos o semiesféricos, dada la cristalinidad de los gránulos. Estos resultados coinciden con lo reportado en la literatura (Cereda, 2000; Hoover, 2002; Jane et al., 1994). En la Figura 2B se observa el almidón nativo de papa con formas típicas ovoides y esféricas. Estas observaciones coinciden con lo reportado en la literatura (Hoover, 2002; Jane et al., 1994). La Figura 2C, muestra las formas típicas de los gránulos de almidón de ñame lenticulares y redondos. Estas observaciones son similares a la reportada en otra investigación (Hoover, 2002).

\section{CONCLUSIONES}

El estudio muestra que existen diferencias en el comportamiento de varias de las propiedades entre los almidones nativos de raíces y tubérculos y la diferencia se debe a la relación de amilosa/amilopectina como se analizó según las propiedades fisico-químicas, la forma y el tamaño del gránulo, como se observó por microscopía óptica de alta resolución y la fuente biológica.

La alta viscosidad de los almidones de ñame y papa en comparación con los almidones nativos de yuca, puede presentar ventajas o desventajas competitivas, dependiendo del tipo de aplicación que se desee desarrollar. Si se quieren desarrollar sopas o alimentos líquidos espesos, lo ideal es trabajar con almidones de alta viscosidad. Si se desarrollan alimentos fluidos sería importante trabajar con almidones de baja viscosidad.

\section{REFERENCIAS}

Alarcón, F. y D. Dufour; Almidón agrio de yuca en Colombia: Tomo 1. Producción y recomendaciones (1998), http://www.ciat.cgiar.org/agroempresas/almidonagrio1.pdf. Acceso: 10 de junio (2007).

Anderson, R.A., H.F. Conway y A.J. Peplinski; Gelatinization of corn grits by roll cooking, extrusion cooking and steaming, Starch/Stärke: 22(4), 130-135 (1970).

AOAC; Métodos de análisis de la asociación oficial de química analítica para determinar humedad, fibra, cenizas, grasa y proteína, chapter 32: 1, 2, 5 y 14, Washintong. U.S.A. (2003).

Bello, P.L.A., Y.P. De Leon, E.A. Acevedo y L.O. Paredes; Isolation and partial characterization of amaranth and banana starches, Starch/Stärke: 50(10), 409-413 (1998).

Cereda, M.P.; Characterization of edible films of cassava starch by electron microscopy, Braz. J. Food Technol., ISNN: 1981-6723 (en línea), 3(40), 2000. http://www.ital.sp.gov.br/bj/artigos/bjft/2000/p0040.pdf. Acceso: 10 de junio (2007). 
DANE; Departamento administrativo nacional de estadística, ministerio de agricultura y desarrollo rural, censo de plantas procesadoras de yuca para uso industrial (2004), http://www.dane.gov.co/files/investigaciones/agropecuario/ena/censoyucaindustrial.pdf. Acceso: 10 de junio (2007).

Fiedorowicz, M., Y.C. Li, y P. Tomasik; Physicochemical properties of potato starch illuminated with visible polarized light, Carboh. Polym.: 50(1), 57-62 (2002).

Hoover, R.; Composition, molecular structure, and physicochemical properties of tuber and root starches: A review, Carboh. polym.: 45(3), 253-267(2001).

Hoover, R; Effect of heat-moisture treatment on the structure and physicochemical properties of tuber and root starches, Carboh. Polym.: 49(4), 425-437 (2002).

Huang, D; Selecting an optimum starch for snack development (2001), http://www.foodinnovation.com/pdfs/Selecting\%200ptimal\%20Starch.pdf. Acceso: 10 de junio (2007).

Hwang, J. y I. Kokini; Contribution of the side branches to rheological properties of pectins, Carboh, Polym.: 19(1), 41-50 (1992).

Imberty, A. y otros cuatro autores; The double helical nature of the crystalline part of A-starch, J. Mol. Biol.: 201(2), 365-378 (1988).

ISO 6647; Norma de la organización internacional para la estandarización sobre determinación de amilosa, 409-414, Génova, Suiza (1987).

Jane, J.L. y otros cuatro autores; Anthology of starch granule morphology by scanning electron microscopy, Starch/Stärke: 46(4), 121-129 (1994).

Jinsong, B., S. Shen, M. Sun y H. Corke; Analysis of genotypic diversity in the starch physicochemical properties of nonwaxy rice: apparent amylose content, pasting viscosity and gel texture, Starch/Stärke: 58(6), 259-267 (2006).

Lindeboom, N., P.R. Chang y R.T. Tyler; Analytical, biochemical and physicochemical aspects of starch granule size, with emphasis on small granule starches: a review, Starch/Stärke: 56(3-4), 89-99 (2004).

Martín, C. y A.M. Smith; Starch biosynthesis, Rev. The plant cell, ISSN: 1059-1524 (en línea), 7 (7), 1995, http://www.pubmedcentral.nih.gov/picrender.fcgi?artid=160895\&blobtype=pdf. Acceso: 10 de junio (2007).

Martínez, H.; Agroindustria y competitividad. La industria procesadora de papa, plátano y yuca: el mercado de pasabocas (snacks) y congelados en Colombia (2005), http://www.agrocadenas.gov.co/documentos/anuario2005/Introduccion.pdf. Acceso: 10 de junio (2007).

Petnamsin, C., N.Y. Termvejsayanon y K. Sriroth; Effect of particle size on physical properties and biodegradability of cassava starch/polymer blend, Kasetsart journal: 34(1), 254-261 (2000).

Rodríguez, W.; Revisión bibliográfica. Botánica, domesticación y fisiología del cultivo de ñame (Dioscorea alata), Rev. Agronomía Mesoamericana, ISSN: 1021-7444 (en línea), 11(2), 2000, http://www.mag.go.cr/rev meso/v11n02 133.pdf. Acceso: 10 de junio (2007).

Sangeetha, M.T.R; Morphology and functional properties of corn, potato and tapioca starches, Food Hydrocolloids: 20(5), 557-566 (2006).

Shamekin, S., P. Myllärihen, K. Poutanen y P. Forssell; Film formation properties of potato starch hydrolysates, Starch/Stärke: 54(1), 20-24 (2002). 
Singh, N., L. Kaur, N.S. Sodhi y K. Sekhon; Physicochemical, cooking and textural properties of milled rice from different Indian rice cultivars, Food Chem: 89(2), 253-259 (2005).

Toshio, O., Y. Tomoyuki, H. Shouji y M. Takaakl; High-resolution Imaging of Starch Granule Structure using Atomic Force Microscopy, Starch/Stärke: 52(5), 150-153 (2000).

Vandeputte, G.E. y J.A. Delcour; From sucrose to starch granule to starch physical behaviour: a focus on rice starch, Carboh. Polym.: 58(3), 245-266 (2004).

Wang, Y.J., V.D. Truong y L. Wang; Structures and rheological properties of corn starch as affected by acid hydrolysis, Carboh. polym.: 52(3), 327-333 (2003). 